\title{
PERILAKU KEPALA KELUARGA DAN KONDISI FISIK RUMAH PENDERITA DIFTERI DI WILAYAH KERJA PUSKESMAS TAMAN DAN WILAYAH KERJA PUSKESMAS SIDOARJO Erniati, Nur Haidah,Iva Rustanti
}

\begin{abstract}
Since 2010-2012 the incidence of diphtheria in Province of East Java have increased. The highest rate of diphtheria incidence occurred in Sidoarjo regency area, at the district of Taman and Sidoarjo.

The purposes of this research describes behavior factors included knowledge, attitude, action of family head of diphtheria patient and the home physical condition of patient covered lighting, humidity, floor type, ventilation and residential density. This research using total sampling with sample population as many 15 family heads of diphtheria patient in 2012.

The result of research indicating that knowledge of family head $80 \%$ was not good caused of bustle in working then information about diphtheria does not gained, attitude $53,3 \%$ was not good because knowledge about diphtheria still low, and action $73,3 \%$ less because knowledge and attitude about diphtheria incidence was low. The house physical condition of diphtheria did not ineligible because of ventilation, humidity, residential density incompatible with health requirements. Whilethe floor type meet the health standarts.

For public health centers in Taman and Sidoarjo should be improving their informing activities about health and clean behavior living as well as increasing DPT (Diphtheria Pertusis Tetanus) immunization coverage for children age 0-15 years old.
\end{abstract}

Keywords : behavior, physical condition of the house

\section{PENDAHULUAN}

Faktor resiko lingkungan penyebab terjadinya penyakit difteri adalah host (umur, jenis kelamin, status imunisasi, status gizi, sosial ekonomi, dan perilaku hidup bersih dan sehat), agent (bakteri Corynebacterium diptheriae) dan environmental (kepadatan hunian, kelembaban, pencahayaan, kondisi lantai, dan ventilasi).

Pada tahun 2012 jumlah kasus penyakit difteri di wilayah kerja Puskesmas Taman sebanyak 7 kasus sedangkan di wilayah kerja Puskesmas Sidoarjo sebanyak 8 kasus. Tingkat kejadian penyakit difteri tertinggi terjadi di kedua wilayah tersebut. Penderita difteri yang ditemukan di masyarakat secara umum memiliki permasalahan terkait dengan kondisi sanitasi rumah dimana secara fisik nampak kurang memenuhi syarat, luas tempat tinggal per orang atau sama dengan kurang dari $4 \mathrm{~m}^{2}$ tiap orangnya, luas ventilasi tempat tinggal kurang dari $10 \%$ dari luas lantai, pencahayaan kurang memenuhi syarat ( $<60$ lux).

Belum adanya genting kaca di atap rumah penderita dan kegiatan maupun jadwal secara rutin yang dilakukan oleh anggota keluarga untuk menjaga maupun meningkatkan kondisi kebersihan lingkungan

\section{Latar Belakang}

rumah dan kegiatan personal hygiene, sehingga bisa mendorong terjadinya penularan penyakit difteri di antara anggota keluarga.

Berdasarkan hasil survei pendahuluann di kedua wilayah tersebut dikarenakan di hasilkan bahwa kondisi fisik rumah yang meliputi pencahayaan, lantai, ventilasi, kelembaban, dan kepadatan hunian kurang memenuhi syarat. Faktor lain yang memepengaruhi meningkatnya kasus difteri adalah perilaku Kepala Keluarga yang meliputi pengetahuan, sikap dan tindakan. Tujuan penelitian untuk mengetahui gambaran perilaku kepala keluarga dan kondisi fisik rumah penderita penyakit difteri.

\section{METODE PENELITIAN \\ Jenis Penelitian \\ Penelitian ini termasuk deskriptif .}

\section{Populasi dan Sampel Penelitian}

Populasi penelitian ini adalah seluruh rumah penderita difteri yang berada di wilayah kerja Puskesmas Taman dan wilayah kerja 
Puskesmas Sidoarjo dengan jumlah 15 penderita.Besar sampel (total populasi).

\section{Sumber Data dan Cara Pengumpulan Data}

Terdiri dari data primer yaitu perilaku kepala keluarga dan kondisi fisik rumah yang diperoleh dari observasi dan pengukuran sedangkan data sekunder diperoleh dari Puskesmas Taman dan Puskesmas Sidoarjo.

\section{Metode Analisis Data}

Analisis data secara deskriptif dengan menilai prosentasenya untuk masing-masing variabel pada 2 wilayah penelitian.

\section{HASIL PENELITIAN}

\section{Data Umum Penderita Difteri di Kecamatan Taman Dan Kecamatan Sidoarjo}

Tabel 1

Prosentase Data Umum Penderita Difteri Di Kecamatan Taman

Dan Kecamatan Sidoarjo Tahun 2013

\begin{tabular}{|c|c|c|c|c|c|}
\hline \multirow[b]{2}{*}{ No } & \multirow[b]{2}{*}{ Variabel Penderita } & \multicolumn{2}{|c|}{ Taman } & \multicolumn{2}{|c|}{ Sidoarjo } \\
\hline & & Jumlah & $\begin{array}{c}\text { Prosentase } \\
(\%)\end{array}$ & Jumlah & $\begin{array}{c}\text { Prosentase } \\
(\%)\end{array}$ \\
\hline \multirow[t]{4}{*}{1} & Jenis Kelamin & & & & \\
\hline & Laki-laki & 3 & 42,8 & 2 & 25 \\
\hline & Perempuan & 4 & 57,2 & 6 & 75 \\
\hline & Total & 7 & 100 & 8 & 100 \\
\hline \multirow[t]{4}{*}{2} & Usia & & & & \\
\hline & $0-15$ tahun & 4 & 57,2 & 7 & 87,5 \\
\hline & $>15$ tahun & 3 & 42,8 & 1 & 12,5 \\
\hline & Total & 7 & 100 & 8 & 100 \\
\hline
\end{tabular}

Dari tabel 1 diperoleh hasil bahwa penderita penyakit difteri di Kecamatan Taman yang berjenis berjenis kelamin perempuan sebanyak $4(57,2 \%)$. Usia penderita berikisar antara 0 15 tahun sebanyak $4(57,2 \%)$.Penderita penyakit difteri di Kecamatan Sidoarjo yang berjenis kelamin perempuan sebanyak 6 (75\%). Usia penderita berkisar antara $0-15$ tahun sebanyak $7(87,5 \%)$.

\section{Data Kepala Keluarga Penderita Difteri di Kecamatan Taman Dan Sidoarjo}

Tabel 2

Prosentase Data Kepala Keluarga Penderita Difteri Di Kecamatan Taman Dan Kecamatan Sidoarjo Tahun 2013

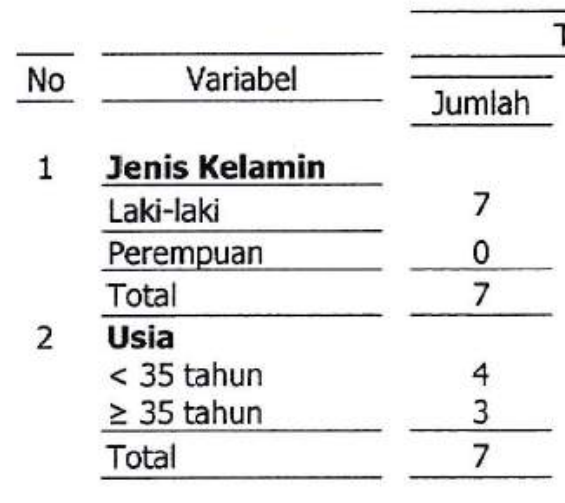

Dari tabel 2 diperoleh hasil bahwa Kepala Keluarga penderita difteri di Kecamatan Taman yang berjenis kelamin laki - laki sebanyak 7 $(100 \%)$ untuk yang berjenis kelamin

\begin{tabular}{|c|c|c|}
\hline Taman & \multicolumn{2}{|c|}{ Sidoarjo } \\
\hline $\begin{array}{c}\text { Prosentase } \\
\text { (\%) }\end{array}$ & Jumlah & $\begin{array}{c}\text { Prosentase } \\
(\%)\end{array}$ \\
\hline 100 & 7 & 87,5 \\
\hline 0 & 1 & 12,5 \\
\hline 100 & 8 & 100 \\
\hline $\begin{array}{l}57,2 \\
42,8\end{array}$ & $\begin{array}{l}4 \\
4\end{array}$ & $\begin{array}{l}50 \\
50\end{array}$ \\
\hline 100 & 8 & 100 \\
\hline
\end{tabular}

perempuan sebanyak $0(0 \%)$. Usia Kepala Keluarga < 35 tahun sebanyak $4(57,2 \%)$ untuk usia Kepala Keluarga $\geq 35$ tahun sebanyak 3 (42,8\%). 
Kepala Keluarga penderita difteri di Kecamatan Sidoarjo yang berjenis kelamin laki - laki sebanyak $7(87,5 \%)$ untuk yang berjenis kelamin perempuan sebanyak $1(12,5 \%)$. Usia
Kepala Keluarga < 35 tahun sebanyak 4 $(50 \%)$ untuk usia Kepala Keluarga $\geq 35$ tahun sebanyak 4 (50\%).

Pengetahuan Kepala Keluarga penderita di Kecamatan Taman dan Sidoarjo sebagaimana terdapat pada tabel berikut ini :

Tabel 3

Distribusi Pengetahuan Kepala Keluarga Penderita Difteri di Kecamatan Taman

Dan Kecamatan Sidoarjo Tahun 2013

\begin{tabular}{cccc}
\hline No & Pengetahuan & Jumlah & Prosentase (\%) \\
\hline 1 & Baik & 0 & 0 \\
\hline 2 & Cukup & 3 & 20 \\
\hline 3 & Kurang & 12 & 80 \\
\hline UMLAH & & 15 & 100 \\
\hline
\end{tabular}

Dari tabel 3 diperoleh hasil bahwa pengetahuan Kepala Keluarga penderita difteri sebagian besar adalah kurang sebanyak 12

$(80 \%)$ dan tidak satu pun yang berpengetahuan baik dan sebagian kecil berpengetahuan cukup sebanyak $3(20 \%)$.

\section{Data sikap Kepala Keluarga di Kecamatan Taman dan Kecamatan Sidoarjo sebagaimana} terdapat pada tabel berikut ini :

Tabel 4

Distribusi Sikap Kepala Keluarga Penderita Difteri di Kecamatan Taman Dan Kecamatan Sidoarjo Tahun 2013

\begin{tabular}{cccc}
\hline No & Sikap & Jumlah & Prosentase (\%) \\
\hline 1 & Baik & 7 & 46,7 \\
\hline 2 & Kurang baik & 8 & 53,3 \\
\hline & JUMLAH & 15 & 100 \\
\hline
\end{tabular}

Dari tabel 4 diatas diperoleh informasi bahwa sikap Kepala Keluarga penderita difteri sebagian besar adalah kurang baik sebanyak $8(53,3 \%)$ dan sebagian kecil bersikap baik sebanyak $7(46,7 \%)$.

Data tindakan Kepala Keluarga penderita difteri di Kecamatan Taman dan Kecamatan Sidoarjo sebagaimana terdapat pada tabel berikut ini :

Tabel 5

Distribusi Tindakan Kepala Keluarga Penderita Difteri di Kecamatan Taman Dan Kecamatan Sidoarjo Tahun 2013

\begin{tabular}{cccc}
\hline No & Tindakan & Jumlah & Prosentase (\%) \\
\hline 1 & Baik & 4 & 26,7 \\
\hline 2 & Kurang baik & 11 & 73,3 \\
\hline & JUMLAH & 15 & 100 \\
\hline
\end{tabular}

Dari tabel 5 diatas diperoleh informasi bahwa tindakan Kepala Keluarga penderita difteri sebagian besar adalah kurang baik sebanyak
$11(73,3 \%)$ dan sebagian kecil termasuk memiliki tindakan yang baik sebanyak 4 $(26,7 \%)$. 
Data kondisi fisik rumah Kepala Keluarga penderita difteri di Kecamatan Taman dan Kecamatan Sidoarjo sebagaimana terdapat pada tabel berikut ini :

Tabel 6

Distribusi Kondisi Fisik Rumah Kepala Keluarga Penderita Difteri di Kecamatan Taman Dan Kecamatan Sidoarjo Tahun 2013

\begin{tabular}{|c|c|c|c|}
\hline No & Variabel & Jumlah & Prosentase (\%) \\
\hline \multirow[t]{4}{*}{1} & Pencahayaan & & \\
\hline & Memenuhi Syarat & 3 & 20 \\
\hline & Tidak Memenuhi Syarat & 12 & 80 \\
\hline & Total & 15 & 100 \\
\hline \multirow[t]{4}{*}{2} & Lantai & & \\
\hline & Memenuhi Syarat & 15 & 100 \\
\hline & Tidak Memenuhi Syarat & 0 & 0 \\
\hline & Total & 15 & 100 \\
\hline \multirow[t]{4}{*}{3} & Ventilasi & & \\
\hline & Memenuhi Syarat & 10 & 66,7 \\
\hline & Tidak Memenuhi Syarat & 5 & 33,3 \\
\hline & Total & 15 & 100 \\
\hline \multirow[t]{4}{*}{4} & Kelembaban & & \\
\hline & Memenuhi Syarat & 8 & 53,3 \\
\hline & Tidak Memenuhi Syarat & 7 & 46,7 \\
\hline & Total & 15 & 100 \\
\hline \multirow[t]{4}{*}{5} & Kepadatan Hunian & & \\
\hline & Memenuhi Syarat & 0 & 0 \\
\hline & Tidak Memenuhi Syarat & 15 & 100 \\
\hline & Total & 15 & 100 \\
\hline
\end{tabular}

Dari data tabel 6 diatas diperoleh hasil bahwa kondisi fisik rumah untuk pencahayaan yang memenuhi syarat sebanyak $3(20 \%)$ untuk pencahayaan yang tidak memenuhi syarat sebanyak 12 (80\%). Untuk lantai rumah penderita difteri yang memenuhi syarat sebanyak $15(100 \%)$. Keadaan ventilasi yang memenui syarat sebanyak $10(66,7 \%)$, untuk PEMBAHASAN

Dari hasil observasi yang dilakukan peneliti diperoleh bahwa kondisi fisik rumah penderita difteri meliputi pencahayaan tidak memenuhi syarat sebesar $80 \%$ hal ini berarti kodisi rumah masih banyak yang gelap, tidaka ada sinar matahari masuk, hal tersebut mamungkinkan berkembangbiakan bibit penyakit akan mudah. Untuk variabel kelembaban rumah,lantai rumah dan ventilasi ramah sebagaian besar sudah memenuhi syarat, sedangkan kepadatan hunian 100\% kurang memenuhi syarat hal ini dapat dilahat bahwa jumlah penghuni rumah tidak sebanding dengan luas rumah yang dimiliki dimana untuk setiap penghuni minimal menempati 4 meter persegi. Jika penghuni rumah terlalu padat maka kemungkinan penularan penyakit pada anggota keluarga besar kemuingkinanannya.

Hasil penelitian tentang perilaku Kepala Keluarga diperoleh hasil pengetahuan $80 \%$ kurang baik, sikap 53,3\% kurang dan tindakan ventilasi yang tidak memenuhi syarat sebanyak $5(33,3 \%)$. Kelembaban rumah penderita difteri yang memenuhi syarat sebanyak $8(53,3 \%)$, untuk kelembaban yang tidak memenuhi syarat sebanyak $7(46,7 \%)$ sedangkan untuk kepadatan hunian rumah yang tidak memenuhi syarat sebanyak 15 (100\%).

$73,3 \%$ kurang. Dari hasil tersebut menunjukkan bahwa kurangnnya pengetahuan masyarakat tentang penyakit difteri mulai dari penyebab, cara penularan dan cara pencegahan penyakit difteri. Pengetahuan yang kurang akan memepengaruhi sikap dan tindakan mereka dalam upaya pengcegahan penyakit difteri. Kemudian dengan kesibukan Kepala Keluarga dalam bekerja sehingga waktu yang ada hanya digunakan untuk melakukan pekerjaan, walaupun tingkat pendidikan Kepala Keluarga sudah baik, namun hal ini tidak menjamin pengetahuan seseorang akan lebih baik karena pengetahuan seseorang bukan hanya ditentukan oleh tingkat pendidikan saja, namun ditentukan pula oleh faktor internal seperti usia Kepala Keluarga yang sebagian besar < 35 tahun dimana hal ini sejalan dengan pendapat dari Nursalam (2008) yang menyatakan bahwa kepercayaan masyarakat akan lebih tinggi bagi mereka yang lebih dewasa, yang mana hal ini akibat dari pengalaman dan kematangan 
jiwanya dimana semakin tua usia seseorang akan semakin konstruktif dalam menggunakan koping terhadap masalah maupun stimulus yang dihadapinnya.

\section{Kesimpulan}

1. Pengetahuan Kepala Keluarga penderita difteri tentang penyebab ,cara penularan dan pencegahan penyakit difteri sebagian besar kurang baik yaitu sebanyak 12 $(80 \%)$, sebagian kecil pengetahuan cukup sebanyak $3(20 \%)$, dan tidak ada yang berpengetahuan baik sebanyak $0(0 \%)$.

2. Sikap Kepala Keluarga penderita difteri tentang persepsi penularan penyakit difteri sebagian besar kurang baik sebanyak 8 $(53,3 \%)$, sedangkan yang bersikap baik sebanyak $7(46,7 \%)$.

3. Tindakan kepala keluarga penderita difteri tentang upaya-upaya pencegahan penularan penyakit difteri sebagian besar kurang baik sebanyak $11 \quad(73,3 \%)$, sedangkan untuk tindakan baik sebanyak 4 $(26,7 \%)$.

4. Kondisi fisik rumah penderita penyakit difteri meliputi penyahayaan $80 \%$ tidak memenuhi syarat, kepadatan penghuni rumah $100 \%$ tidak memenuhi syarat

\section{Saran}

1. Bagi Puskesmas Taman dan Puskesmas Sidoarjo : hendaknya meningkatkan kegiatan-kegiatan penyuluhan tentang penyakit difteri serta meningkatkan cakupan imunisasi DPT (Difteri Pertusis Tetanus) untuk anak usia $0-15$ tahun sehingga dapat mencegah proses penularan penyakit difteri di masyarakat

2. Bagi masyarakat:
a. Kepala Keluarga hendaknya meluangkan waktunya agar informasi tentang penyakit difteri yang telah banyak diinformasikan oleh Petugas Puskesmas maupun media lainnya dapat diketahuinya sehingga dapat meningkatkan pengetahuan serta mendorong upaya-upaya pencegahan penyakit difteri tersebut agar tidak terjangkit di keluarganya.
b. Kepala keiuarga hendaknya memperhatikan kondisi fisik rumah dengan pemasangan genteng kaca dan kebersihan lingkungan rumah dengan mengatur tata ruang rumah yang sesuai persyaratan kamar tidur yaitu $4 \mathrm{~m}^{2}$ per orang.

\section{DAFTAR PUSTAKA}

Azwar, Azrul, 1995. Pengantar Ilmu Kesehatan Lingkungan, Jakarta, Mutiara Sumber Widya.
Gunawan, Rudy, Haryanto. 1979. Pedoman Perencanaan Rumah Sehat. Yogyakarta, Yayasan Sarana Cipta : 9.

Irianto, Koes, 2007. Mikrobiologi Menguak Dunia Mikroorganisme. Bandung, CV Yrama Widya : 46,47.

Kartono, Basuki. 2007. Lingkungan Rumah dan Kejadian Difteri di Kabupaten Tasikmalaya dan Kabupaten Garut. Jurnal Makara kesehatan, vol..12, no. 1, juni 2008: 8-12

Kesmas, 2012. Faktor Risiko Difteri, http : // www. Indonesianpublichealth.com/2012/11/faktor-risikodifteri.html. Diakses pada tanggal 13 Maret 2013 pukul 13:00 WIB.

Mandal, B.K, dkk, 2008. Penyakit Infeksi. Jakarta, PT . Gelora Aksara Pratama : 4, 36.

Maulana, Heri D. J. 2009. Promosi Kesehatan. Jakarta, EGC : 196

Meylinda, Putri. 2012. Pengaruh Kondisi Fisik Rumah, Status Imunisasi, Dan Pengetahuan Ibu Terhadap Kejadian Difteri Pada Bayi Di Kota Surabaya. Jurnal Unesa IImu Sosial

Mufidah, Fatchul, 2012. Cermati PenyakitPenyakit Yang Rentan Diderita Anak Usia Sekolah. Jogjakarta, FlashBooks : $66-73$.

Notoatmodjo, Soekidjo, 2003. Pendidikan Dan Perilaku Kesehatan. Jakarta, PT. Rineka Cipta : 3,121,127,130,133,151.

Notoatmodjo, Soekidjo, 2003. Ilmu Kesehatan Masyarakat Prinsip-Prinsip Dasar, Jakarta, PT Rineka Cipta : 38,39,151.

Notoadmojo, Soekidjo, 2005. Metode Penelitian Kesehatan. Jakarta, PT. Rineka Cipta : 146

Notoatmodjo, Soekidjo, 2007. Promosi Kesehatan Dan Ilmu Perilaku. Jakarta, PT. Rineka Cipta : 133 - 145

Notoatmodjo, Soekidjo, 2010, Metodologi Penelitian Kesehatan, Jakarta : Rineka Cipta

Nursalam (2008). Konsep dan Penerapan Metode Penelitian I/mu Keperawatan. Jakarta : Salemba Medika

Setiasih, Asih, 2011. Faktor Risiko Kejadian Difteri Di Kota Surabaya Propinsi Jawa Timur, Tesis Ilmu Kesehatan Masyarakat Pasca Sarjana Fakultas Kedokteran UGM Yogyakarta.

Suharmadi, 1985. Perumahan Sehat. Bandung, Proyek Pengembangan Pendidikan Tenaga Sanitasi Pusat : 1.

Suyono, Budiman, 2012. Ilmu Kesehatan Masyarakat Dalam Konteks Kesehatan Lingkungan. Jakarta, Buku Kodokteran EGC : 20,84 . 